\title{
Relationships Between the Cytotoxicity of Tiazofurin and Its Metabolism by Cultured Human Lung Cancer Cells
}

\author{
Desmond N. Carney, Gurpreet S. Ahluwalia, Hiremagalur N. Jayaram, David A. Cooney, and David G. Johns \\ National Cancer Institute-Navy Medical Oncology Branch, and Laboratory of Medicinal Chemistry and Pharmacology, \\ Developmental Therapeutics Program, Division of Cancer Treatment, National Cancer Institute, \\ National Institutes of Health, Bethesda, Maryland 20205
}

\begin{abstract}
The antitumor activity of the antineoplastic agent, tiazofurin (2- $\beta$-D-ribofuranosylthiazole-4-carboxamide), has previously been shown to require intracellular anabolism of the drug to a nicotinamide adenine dinucleotide (NAD) analog (2- $\beta$-Dribofuranosylthiazole-4-carboxamide adenine dinucleotide or "tiazofurin adenine dinucleotide"), which then acts as a potent inhibitor of the target enzyme inosine monophosphate (IMP) dehydrogenase. Inhibition of the latter enzyme in turn brings about a profound depletion of intracellular guanosine nucleotides essential for tumor cell growth and replication. In the present study, the cytotoxicity and metabolism of tiazofurin have been examined in six human lung cancer cell lines. At the pharmacologically attainable drug concentration of $100 \mu \mathrm{M}$, colony survival was $<1.5 \%$ in three cell lines ("sensitive"), while survival in the remaining three was $>50 \%$ ("resistant"). The metabolism of tritiated tiazofurin was examined at concentrations ranging from 0.5 to $100 \mu \mathrm{M}$ following both brief (6 h) and protracted (14 d) exposures. The sensitive lines accumulated concentrations of tiazofurin adenine dinucleotide that were approximately 10 times those achieved by the resistant lines at both time points. We also observed tendencies for the sensitive cell lines to exhibit: (a) higher specific activities of NAD pyrophosphorylase, the enzyme required for the synthesis of tiazofurin adenine dinucleotide, (b) significantly lower levels of a phosphodiesterase which degrades the latter dinucleotide, (c) greater inhibition of the target enzyme IMP dehydrogenase, and $(d)$ greater depressions of guanosine nucleotide pools after drug treatment. By contrast, the basal levels of IMP dehydrogenase and purine nucleotides in these six lines did not correlate in any obvious way with their responsiveness or resistance. The accumulation and monophosphorylation of parent drug were also not prognostic variables. These studies thus suggest that the extent of accumulation of tiazofurin adenine dinucleotide, as regulated by its synthetic and degradative enzyme activities, is the single most predictive determinant of
\end{abstract}

These studies have been presented in part at the 75th Annual Meeting of the American Society for Clinical Investigation, Washington, DC, 29 April-2 May 1983, and have appeared in abstract form (1983. Clin. Res. 31:507A). The opinions expressed herein are those of the authors and are not to be construed as reflecting the views of the Navy Department, of the Naval Service at large, or of the Department of Defense.

Address correspondence to Dr. Johns. Dr. Carney's current address is Department of Medical Oncology, Mater Misericordiae Hospital, Dublin, Ireland.

Received for publication 3 February 1984 and in revised form 6 September 1984.

The Journal of Clinical Investigation, Inc.

Volume 75, January 1985, 175-182 the responsiveness of cultured human lung tumor cells to tiazofurin.

\section{Introduction}

The C-nucleoside tiazofurin, (2- $\beta$-D-ribofuranosylthiazole-4carboxamide, Fig. 1), an analogue of the potent antiviral agent ribavirin (1), has demonstrated significant antitumor activity against the L1210 and P388 murine leukemias and is curative of the Lewis lung carcinoma (2). In vitro studies with four human malignant lymphoid cell lines established that the $50 \%$ inhibitory concentrations of tiazofurin were $30,27,7$, and 6 $\mu \mathrm{M}$, which are values between 3 and 15 times higher than the $50 \%$ inhibitory concentration of the drug for P388 lymphocytes in culture $(3,4)$. In metabolic studies, tiazofurin has been shown to depress guanosine nucleotide biosynthesis through its inhibition of inosine monophosphate dehydrogenase (IMPD)! (Fig. 2) (4, 5). This inhibition in turn has been attributed to the formation of an analogue of nicotinamide adenine dinucleotide (NAD), tiazofurin adenine dinucleotide (TAD), in which the thiazole ring of tiazofurin has replaced nicotinamide $(6,7)$ (Fig. 1). In vitro, this "fraudulent" dinucleotide inhibits partially purified preparations of IMPD with an inhibition constant $\left(K_{i}\right)$ of $0.2 \mu \mathrm{M}$. Levels of TAD at least one order of magnitude greater than this have been shown to be formed in vivo (7). Inasmuch as tiazofurin is presently being evaluated in phase I-II, clinical trials in patients with cancer, including lung cancer, we have evaluated the in vitro cytotoxicity of the drug in six human lung cancer cell lines using a soft agarose clonogenic assay. In addition, the metabolism of the drug was examined. The results of these experiments suggest that, in human lung cancer cells, the extent of accumulation of TAD, the proposed active metabolite of tiazofurin, may be the most important predictor of sensitivity of these cells to the drug.

\section{Methods}

Tiazofurin (NSC 286193) was provided by the Drug Synthesis and Chemistry Branch, National Institutes of Health. [5- ${ }^{3} \mathrm{H}$ ]Tiazofurin $(1.96 \mathrm{Ci} / \mathrm{mmol})$ was obtained from Research Triangle Institute, Research Triangle Park, NC, through the courtesy of Dr. Robert Engle of NCI. The metabolites of tiazofurin (its mono-, di-, and triphosphates, and TAD) were synthesized and provided by Dr. Victor Marquez of NCI. [2- $\left.{ }^{3} \mathrm{H}\right] \mathrm{H}$ ypoxanthine $(4.9 \mathrm{Ci} / \mathrm{mmol})$ for the synthesis of labeled inosine monophosphate (IMP) (4) and $\left[2-{ }^{3} \mathrm{H}\right]$ adenosine triphosphate (ATP) (25 Ci/mmol) for the synthesis of labeled TAD were purchased from Amersham/Searle, Arlington Heights, IL. Yeast alcohol dehydrogenase

1. Abbreviations used in this paper: HPLC, high performance liquid chromatography; IMP, inosine monophosphate; IMPD, IMP dehydrogenase; NCI, National Cancer Institute; SCLC, small cell lung cancer; TAD, tiazofurin adenine dinucleotide; TRMP, tiazofurin-5'-monophosphate. 

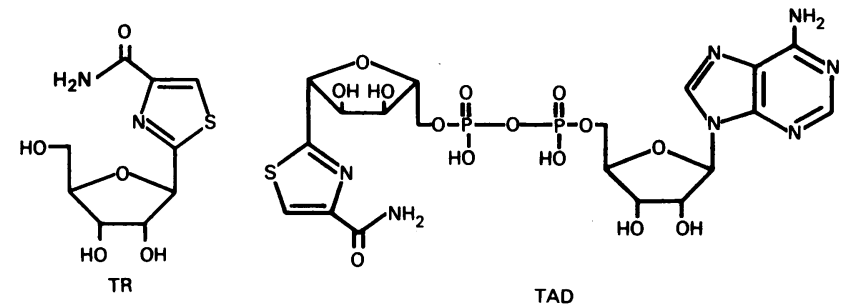

Figure 1. Structure of tiazofurin (TR) and its metabolite, TAD.

(300 U/mg) and hog liver NAD pyrophosphorylase were the product of Boehringer Mannheim Corp., Indianapolis, IN. All other reagents used were of the highest purity available.

Methods for the growth and characterization of the cell lines used in this study have been described previously (8-11). Briefly, all cultures were established from patients with a histologically confirmed diagnosis of lung cancer and maintained in RPMI 1640 culture medium (Gibco Laboratories, Grand Island, NY) supplemented with $10 \%$ heat-inactivated fetal bovine serum. The cell lines evaluated included four derived from patients with small cell lung cancer (SCLC) (H82, H146, H249, and N417), and two derived from patients with adenocarcinoma of the lung (H23 and H125). The in vitro doubling times of the lines were: H23 (38 h); H82 (33 h); H125 (39 h); H146 (54 h); H249 (36 h); and N417 ( $24 \mathrm{~h})$. The SCLC cell lines could be divided into two groups: classic SCLC cell lines (SCLC-C, H146, and H249) and variant SCLC cell lines (SCLC-V, H82, and N417). The SCLC-C cell lines have typical SCLC morphology, grow as floating cell aggregates, and express elevated levels of $L$-dopa decarboxylase (E.C. 41.1.28), neuron specific enolase, creatine kinase $\mathrm{BB}$, and the peptide hormone bombesin $(8,10,11)$. In contrast, the SCLC-V cell lines, which also grow as floating aggregates of cells, do not express typical SCLC amine precursor uptake and decarboxylation markers including L-dopa decarboxylase or peptide hormones $(8,10,11)$. However, in contrast to non-SCLC cells, the SCLC-V exhibit the SCLC properties of elevated levels of creatine kinase BB. At the time of in vitro drug-testing, all cell lines had been maintained in continuous culture for periods ranging from 2 to $4 \mathrm{yr}$. All lines had human isozymes, and formed tumor cell

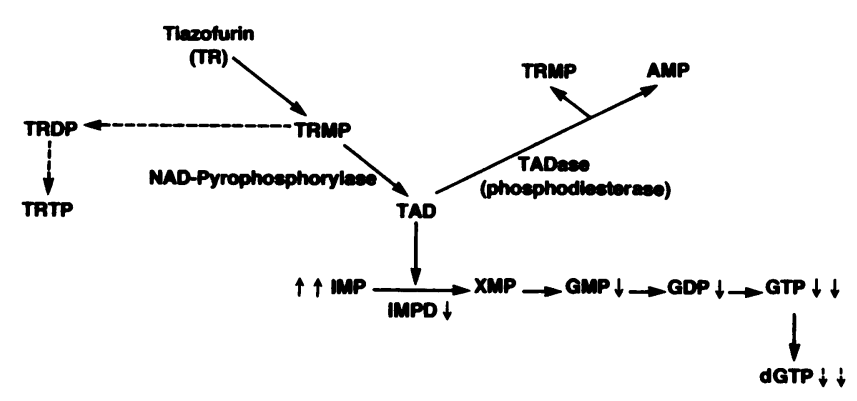

Figure 2. Mode of action of tiazofurin. Intracellularly, tiazofurin is phosphorylated by an as yet unidentified kinase to yield its monophosphate. This nucleotide is then either utilized (in lieu of nicotinamide mononucleotide) by the nuclear enzyme NAD pyrophosphorylase in the presence of ATP to yield TAD, or, in certain tissues, further phosphorylated to yield tiazofurin di- and triphosphates. TAD is a potent but reversible inhibitor of inosinic acid dehydrogenase, its $K_{\mathrm{i}}$ being $\sim 0.2 \mu \mathrm{M}$. As long as the concentration of TAD prevails at or exceeds this level, the synthesis of xanthosine monophosphate (XMP) will be substantially depressed. In the face of the resultant deprivation of guanosine monophosphate (GMP) (and so of guanosine diphosphate (GDP), guanosine triphosphate (GTP), and deoxyguanosine triphosphate (dGTP), the synthesis of nucleic acids is depressed or arrested, leading to cell death or cytostasis in susceptible tumors. colonies in soft agarose and tumors with characteristic lung cancer morphology in athymic mice. In all studies, cell lines were harvested in $\log$ growth phase at $\mathbf{2} \mathrm{d}$ following a medium change. All cell lines were repeatedly tested for mycoplasma contamination and were found to be free of it, as determined both by Hoechst stain and by growth in enriched mycoplasma broth and agar (Microbiological Associates, Bethesda, MD).

\section{In vitro test of cytotoxicity}

Sensitivity of the six cell lines to tiazofurin was tested using a soft agarose clonogenic assay as previously described (12-15). Single cell suspensions of viable cells in log phase growth were mixed with varying concentrations of tiazofurin to yield final drug concentrations of 1 $\mu \mathrm{M}-10 \mathrm{mM}$, and were then suspended in culture medium fortified with $0.3 \%$ agarose (Sea Kem, Rockland, MA). $1 \mathrm{ml}$ of the mixture was plated in triplicate in $35-\mathrm{mm}$ plastic petri dishes containing a base layer of solidified $0.5 \%$ agarose in culture medium. The number of cells plated, ranging from $10^{4}$ to $10^{5}$, was chosen so that a minimum number of 200-500 colonies (cell aggregates $>50$ cells) would be obtained in control plates. For each experiment, tiazofurin was freshly prepared in phosphate-buffered saline. All cultures and tests were performed in triplicate. Cultures were incubated at $37^{\circ} \mathrm{C}$ in a wellhumidified atmosphere of $5 \% \mathrm{CO}_{2}: 95 \%$ air. Plates, examined with an inverted phase microscope, were initially checked to confirm that only single cells had been plated. After $14 \mathrm{~d}$ of culture, when colony size and viability were optimal, colonies were scored. Colony growth in drug-treated plates was compared with growth in control plates and results expressed as percentage of colony growth observed in control plates.

To determine the effect of short-term exposure, cells were first incubated with the drug for $6 \mathrm{~h}$ in liquid culture and then resuspended in tiazofurin-free culture medium fortified with $0.3 \%$ agarose. Subsequent treatment of the cultures was then identical with that described above, with colonies being scored at $14 \mathrm{~d}$.

\section{Determination of tiazofurin metabolites}

Short-term incubations. Cell lines were treated with tiazofurin at three different concentrations of the drug $(1,10$, and $100 \mu \mathrm{M}$, along with tritiated drug, $50 \mu \mathrm{Ci} /$ flask). After $6 \mathrm{~h}$ of exposure to the drug, cells were centrifuged at $1000 \mathrm{~g}$ in a Sorvall centrifuge (Ivan Sorvall Inc., Newtown, CT) for 3 min. The cell pellet was washed with cold Hanks' balanced salt solution, pelleted through Versilube oil (General Electric Co., Waterford, NY), and extracted with $500 \mu$ l of $10 \%$ trichloroacetic acid (TCA). The protein-free supernatant was neutralized with $0.5 \mathrm{M}$ trioctylamine in freon (16). Neutralized samples were loaded onto a Partisil 10-SAX column (Waters Associates, Milford, MA) preequilibrated with $0.03 \mathrm{M}$ ammonium phosphate buffer, $\mathrm{pH}$ 3.5. Tiazofurin and its metabolites were eluted using a linear gradient of $0.03 \mathrm{M}$ ammonium phosphate, $\mathrm{pH} 3.5$, to $0.6 \mathrm{M}$ ammonium phosphate, $\mathrm{pH}$ 4.6 (6); under these conditions, tiazofurin, tiazofurin-5'-monophosphate (TRMP) and TAD eluted at 3, 7, and 18 min, respectively. Metabolite concentrations were quantitated by measuring the radioactivity eluting in these peaks.

Long-term incubation. Long-term incubations were carried out essentially as described above except that tritiated tiazofurin was present for a full 14-d incubation at a concentration of $0.5 \mu \mathrm{M}, 50$ $\mu \mathrm{Ci}$ /flask.

\section{Nucleotide pools}

Human cancer cells were treated with either normal saline or $100 \mu \mathrm{M}$ tiazofurin for $6 \mathrm{~h}$. Following drug treatment, cells were quickly removed and centrifuged. Washed cell pellets were treated with $10 \%$ TCA. Acid extracts were neutralized and analyzed by high pressure liquid chromatography (HPLC) as described earlier.

\section{Enzyme analyses}

Sample preparation. Cells were washed with cold Hanks' balanced salt solution. Washed cell pellets were homogenized in $4 \mathrm{vol}$ of $0.25 \mathrm{M}$ 
sucrose, containing $1 \mathrm{mM}$ dithiothreitol and $20 \mathrm{mM}$ Tris- $\mathrm{HCl}, \mathrm{pH}$ 7.5. Homogenates were centrifuged at $3,000 \mathrm{~g}$ for $10 \mathrm{~min}$ in a refrigerated Sorvall centrifuge (Ivan Sorvall Inc.). Pellets obtained were washed twice with the homogenization buffer to remove any cytosolic contaminants. The resultant pellet was resuspended in buffer containing

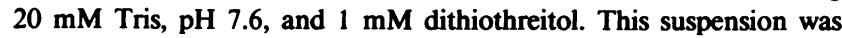
used as a source of enzyme for NAD-pyrophosphorylase assays. A portion of the $3,000 \mathrm{~g}$ supernatant from the above step was reserved for measurement of any unsedimented NAD pyrophosphorylase; the remainder was centrifuged at $13,000 \mathrm{~g}$ for $2 \mathrm{~min}$ and the resultant supernatant used for IMPD and TAD-phosphodiesterase assays.

$N A D$-pyrophosphorylase assay. The activity of this enzyme was measured by a modification of the method of Pinder et al. (17). The enzyme extract (prepared as described above) was incubated in an assay medium consisting of $3.0 \mathrm{mM} \mathrm{ATP}, 7.5 \mathrm{mM} \mathrm{MgCl}_{2}, 0.2 \mathrm{M}$ nicotinamide, $25 \mathrm{mM}$ glycylglycine buffer, $\mathrm{pH} 7.6$, with or without $8.0 \mathrm{mM}$ nicotinamide mononucleotide, in a total assay volume of 0.5 $\mathrm{ml}$. Incubations were carried on for $20 \mathrm{~min}$ at $37^{\circ} \mathrm{C}$, after which the reaction was stopped by heating in a boiling water bath for 1 min. Any NAD formed was quantified by its conversion to NADH with alcohol dehydrogenase (17). NAD-Pyrophosphorylase activity was calculated by measuring the difference in absorbance at $340 \mathrm{~nm}$ before and after alcohol dehydrogenase treatment.

Measurement of TAD-phosphodiesterase. TAD-phosphodiesterase activity was measured in the homogenate and supernatant fraction of the six cell lines described above. Radiolabeled TAD, substrate for this enzyme, was synthesized enzymatically using purified hog liver NADpyrophosphorylase. The reaction mixture for TAD synthesis contained $0.15 \mathrm{mCi}$ of $\left[{ }^{3} \mathrm{H}\right] \mathrm{ATP}$ (specific activity, $125 \mathrm{mCi} / \mathrm{mmol}$ ), $50 \mathrm{mM}$ TRMP, $10 \mathrm{mM} \mathrm{MgCl}, 15 \mathrm{mg}$ of purified enzyme protein, and 0.06 $\mathrm{M}$ Tris- $\mathrm{HCl}, \mathrm{pH} 7.6$, in a total volume of $1 \mathrm{ml}$. After $6 \mathrm{~h}$ of incubation at $37^{\circ} \mathrm{C}$, the reaction was stopped by heating for $1 \mathrm{~min}$ in a boiling water bath. $\left[{ }^{3} \mathrm{H}\right] \mathrm{TAD}$ was purified from this reaction mixture using a $\mathrm{C}_{18}$ semipreparative HPLC column (Waters Associates). [ $\left.{ }^{3} \mathrm{H}\right]$ TAD was well separated from the rest of the constituents using isocratic elution with $0.06 \mathrm{M}$ ammonium formate (native $\mathrm{pH}$ ). Fractions containing $\left[{ }^{3} \mathrm{H}\right] \mathrm{TAD}$ were pooled and repeatedly lyophilized until a salt-free preparation was achieved. Purity of this preparation was found to exceed $95 \%$ on an anion exchange HPLC system (supra). For the determination of TAD-phosphodiesterase, the specific activity of labeled TAD was adjusted using pure, chemically synthesized TAD. The reaction mixture for the TAD-phosphodiesterase assay contained: 5 $\mathrm{mM}\left[{ }^{3} \mathrm{H}\right] \mathrm{TAD}$ (sp. act., $14 \mu \mathrm{Ci} / \mu \mathrm{mol}$ ), $0.03 \mathrm{M} \mathrm{MgCl}_{2}, 20 \mathrm{mM}$ Tris$\mathrm{HCl}, \mathrm{pH} 7.6$, and $0.01-0.06 \mathrm{mg}$ of the sample protein in a total volume of $15 \mu \mathrm{l}$. After $30 \mathrm{~min}$ of incubation at $37^{\circ} \mathrm{C}$, the reaction was stopped by heating for $1 \mathrm{~min}$ at $95^{\circ} \mathrm{C}$. The radiolabeled product resulting from the degradation of $\left[{ }^{3} \mathrm{H}\right] \mathrm{TAD},\left[{ }^{3} \mathrm{H}\right]$ adenosine monophosphate (AMP), was isolated on miniature columns of Dowex 1-X8 formate form as follows: A slurry of Dowex resin made in $0.25 \mathrm{M}$ ammonium formate (native $\mathrm{pH}$ ) was gently poured into a Pasteur pipette column containing a glass wool plug at the bottom. The sample from the above assay was diluted with $100 \mu \mathrm{l}$ of $0.25 \mathrm{M}$ ammonium formate and loaded onto the column. The column was washed once with $0.5 \mathrm{ml}$ of $0.25 \mathrm{M}$ ammonium formate buffer and eluted with 4.0 $\mathrm{ml}$ of $1.0 \mathrm{M}$ ammonium formate (native $\mathrm{pH}$ ). Under these conditions, [ $\left.{ }^{3} \mathrm{H}\right]$ AMP was eluted quantitatively, leaving TAD bound to the column. Degradation of TAD was calculated based on the radiolabeled AMP generated during the enzyme assay.

\section{IMPD assay and kinetic studies}

To $1 \mathrm{ml}$ of cell supernatant was added $100 \mu$ l of ice-cold $1 \mathrm{M}$ sodium acetate, $\mathrm{pH} \mathrm{5.0}$; after $5 \mathrm{~min}$ at $4^{\circ} \mathrm{C}$, the precipitate which formed was collected by centrifugation and resuspended in the homogenizing buffer. This acid precipitation step yielded a 10-fold increase in the specific activity of IMPD compared with the crude homogenate.

For kinetic studies, vessels were set up in triplicate with a fourth vessel serving as a blank. All vessels received $5 \mu \mathrm{l}$ of $0.5 \mathrm{M} \mathrm{KCl}$ containing $10 \mathrm{mM}$ uridine and $2.6 \mu \mathrm{M}$ allopurinol at pH 8.0. Controls received $5 \mu \mathrm{l}$ of $0.1 \mathrm{mM}$ mycophenolic acid (to totally inhibit IMPD activity). Vessels were allowed to dry at room temperature overnight $(16 \mathrm{~h})$. This drying step did not affect the stability of the constituents listed above. At the time of assay, the vessels received $5 \mu$ l of [2${ }^{3} \mathrm{H}$ ]IMP $\left(2.86 \times 10^{-4} \mathrm{M} ; 220 \mu \mathrm{Ci} / \mathrm{ml}\right.$; specific radioactivity, $738 \mathrm{mCi}$ / mmol); $5 \mu$ l of NAD (0.6-2.0 mM) in 0.05 M Tris buffer, pH 8.0; 5 $\mu \mathrm{l}$ of TAD $(0.25-1.0 \mu \mathrm{M})$ in $0.05 \mathrm{M}$ Tris buffer, $\mathrm{pH} 8.0$; or buffer alone and $5 \mu$ l of the enzyme preparation. Reactants were admixed by a 5-s centrifugation at $12,000 \mathrm{~g}$ and incubated at $37^{\circ} \mathrm{C}$ for $10 \mathrm{~min}$; the reaction was terminated by heating at $95^{\circ} \mathrm{C}$ for $1 \mathrm{~min}$. Vessels were centrifuged for $1 \mathrm{~min}$ at $12,000 \mathrm{~g}$, and tritiated water was distilled and trapped in $5 \mu \mathrm{l}(3 \times 1.6 \mu \mathrm{l})$ droplets of $100 \% \mathrm{KOH}(\mathrm{wt} / \mathrm{vol})$ deposited on the underside of the vessel's lid. After $16 \mathrm{~h}$ at room temperature, lids were cut off and the tritiated water counted by scintillation spectrometry.

\section{Results}

In vitro cytotoxicity. The results of in vitro cytotoxicity testing following 6-h exposure and 14-d continuous exposure are shown in Figures $3 A$ and $3 B$. Following a 6-h exposure, significant inhibition of colony formation was observed in three cell lines, $\mathrm{H} 23, \mathrm{H} 82$, and $\mathrm{N} 417$, at a concentration of $10 \mathrm{mM}$. No inhibition was observed in the three remaining cell lines. Following a 14-d continuous exposure to tiazofurin, considerable heterogeneity in the dose-response of these lines was observed: thus, the $50 \%$ inhibitory concentrations ranged from $\sim 10$ to $\sim 500 \mu \mathrm{M}$. At a concentration of $10^{-4} \mathrm{M}$, the six cell lines could be divided into two groups based on their relative sensitivity to tiazofurin. Three cell lines, N417, H82, and $H 23$, had colony survival of $<1.5 \%$ (Fig. $3 B$ ) and were considered to be "sensitive" to tiazofurin, while the remaining three cell lines, at the same drug concentration, had colony survival ranging from 50 to $75 \%$ and were labeled "resistant." Repetition of these studies on the same lines 12 mo later yielded virtually identical results.

Short-term accumulation and metabolism of tiazofurin by human lung cancer cell lines in culture. $6 \mathrm{~h}$ after treatment with tiazofurin $(1,10$, and $100 \mu \mathrm{M}, 50 \mu \mathrm{Ci} /$ flask), drug metabolites were analyzed by HPLC (Table I). The six lines accumulated parent drug to variable degrees, but the intracellular drug concentrations achieved did not correlate in any

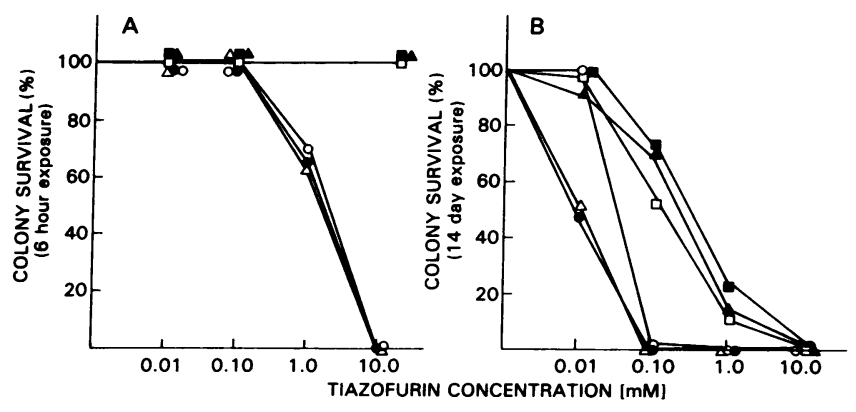

Figure 3. Single cell suspension of viable human lung cancer cell lines, N417 (-o-, SCLC-V); H82 (- - , SCLC-V); H249 (- --, SCLC-C); H146 (---, SCLC-C); H23 (-•-, adenocarcinoma); and $\mathrm{H} 125(-\triangle-$, adenocarcinoma) in triplicate were treated with tiazofurin $\left(10^{-2}-10^{-6} \mathrm{M}\right)$, and the sensitivity or resistance to the drug was determined by soft agarose clonogenic assay as described in Methods. $(A)$ Short-term $(6 \mathrm{~h})$ exposure to drug; $(B)$ Long-term (14 d) exposure to drug. In all cell lines the number of colonies in control plates was $>200$; the number of colonies in replicate plates was within $\pm 10 \%$ (SD) of the mean of triplicate samples. 
obvious way with the sensitive or resistant nature of these lines. Incubation with increasing concentrations of drug produced a parallel increase in drug accumulation in all cell lines with no indication of saturation up to $100 \mu \mathrm{M}$. Similar results were obtained for the accumulation of TRMP where the observed levels showed no strict correlation either with the concentration of precursor (tiazofurin) or with sensitivity to the drug. By contrast, TAD accumulation showed marked differences in the two groups: thus, in the sensitive line, exposed to $100 \mu \mathrm{M}$ drug, TAD accumulated to concentrations ranging from 1.1 to $2.1 \mathrm{nmol} / 10^{6}$ cells compared with 0.05 $0.37 \mathrm{nmol} / 10^{6}$ cells in the resistant group. A dose-dependent accumulation of TAD was observed in all cell lines, again with no evidence of saturation.

Long-term accumulation and metabolism of tiazofurin by human lung cancer cell lines in culture. When the six lines included in the present study were incubated with tritiated tiazofurin $(0.5 \mu \mathrm{M})$ for $14 \mathrm{~d}$, the extent of accumulation of TAD again showed a strong correspondence to their sensitivity or resistance to the drug (Table I). Thus, the mean concentration of the inhibitory dinucleotide in the "resistant" lines was, on the average, 10 times lower than the levels measured in responsive cells. From this result, it can be concluded that the positive correlation between sensitivity to tiazofurin and accumulation of TAD is not due to transitory factors, but persists under circumstances ( $14 \mathrm{~d}$ of exposure) in which steady-state conditions were very likely to have been approached.

Enzymology of TAD synthesis. Since the accumulation of TAD was found to be notably greater in the sensitive as compared with the resistant lines, a logical next step was to examine the enzymology of its synthesis. This anabolite is formed from tiazofurin in a two-step process (Fig. 2). The first enzymatic step is the conversion of tiazofurin to its 5 -monophosphate, TRMP. Since the accumulation of TRMP was found to be roughly similar in all cell lines studied, the possibility that the phosphorylation step is impaired in the resistant lines was ruled out. The critical step resulting in TAD accumulation is believed to be the conversion of TRMP to TAD. The enzyme NAD-pyrophosphorylase has been identified as catalyzing this reaction (6), with TRMP and ATP as substrates. Although overlaps and variability were observed for this activity in the two groups (Table II), the sensitive lines exhibited a mean specific activity of NAD-pyrophosphorylase which was $212 \%$ of the activity in the resistant lines.

Enzymology of TAD breakdown. Using labeled TAD as substrate, it was possible to examine the capability of the six human lung tumor cell lines to catalyze the phosphodiesteratic degradation to TAD to its constituent nucleotides, TRMP and AMP (Table II). This activity, which was largely soluble, was significantly lower in the sensitive lines $(43.3 \mathrm{nmol} / \mathrm{h} / \mathrm{mg}$ protein) than in their resistant counterparts $(159.9 \mathrm{nmol} / \mathrm{h} / \mathrm{mg}$ protein).

Influence of tiazofurin treatment on IMPD activity in cultured human cell lines. It has been shown previously that TAD is a potent inhibitor of IMPD $(6,7)$. IMPD activity was measured in the sensitive and resistant lines treated with tiazofurin $(100 \mu \mathrm{M}, 6 \mathrm{~h})$ or saline. Some variability was observed in the basal activity of this enzyme in the six cell

Table I. Metabolism of Tiazofurin by Cultured Human Tumor Cells

\begin{tabular}{|c|c|c|c|c|c|c|c|}
\hline \multirow[b]{2}{*}{ Drug or drug anabolite } & \multirow{2}{*}{$\begin{array}{l}\text { Concentration } \\
\text { of tiazofurin }\end{array}$} & \multicolumn{6}{|l|}{ Concentration } \\
\hline & & H82 (S) & N417 (S) & H23 (S) & H146 (R) & H125 (R) & H249 (R) \\
\hline & $\mu M$ & pmol/10 $10^{\circ}$ cells & pmol $/ 10^{\circ}$ cells & pmol/10 $10^{6} \mathrm{cells}$ & pmol $/ 10^{6} \mathrm{cells}$ & $\mathrm{pmol} / 10^{6} \mathrm{cells}$ & $\mathrm{pmol} / 10^{6}$ cells \\
\hline \multicolumn{8}{|c|}{ Short-term incubation } \\
\hline \multirow[t]{3}{*}{ TR } & 1 & 4 & 8 & 10 & 4 & 5 & 11 \\
\hline & 10 & 54 & 84 & 106 & 37 & 77 & 116 \\
\hline & 100 & 766 & 620 & 1610 & 590 & 699 & 1980 \\
\hline \multirow[t]{3}{*}{ TRMP } & 1 & 4 & 2 & 12 & 8 & 2 & 12 \\
\hline & 10 & 28 & 21 & 83 & 71 & 125 & 126 \\
\hline & 100 & 205 & 421 & 851 & 485 & 1380 & 1550 \\
\hline \multirow[t]{3}{*}{ TAD } & 1 & 17 & 37 & 33 & 1 & 3 & 8 \\
\hline & 10 & 120 & 222 & 257 & 4 & 43 & 55 \\
\hline & 100 & 1110 & 1510 & 2100 & 47 & 263 & 370 \\
\hline \multicolumn{8}{|c|}{ Long-term incubation } \\
\hline TR & 0.5 & 0.38 & 0.58 & 0.19 & 0.30 & 0.08 & 0.44 \\
\hline TRMP & 0.5 & 0.19 & 0.23 & 0.05 & 0.10 & 0.02 & 0.41 \\
\hline TAD & 0.5 & 0.49 & 0.81 & 0.82 & 0.07 & 0.05 & 0.08 \\
\hline
\end{tabular}

TR, tiazofurin. Short-term incubations. The six cultures, in triplicate, at densities of $1-3 \times 10^{5} \mathrm{cells} / \mathrm{ml}$, were verified to be in logarithmic growth and then were treated with radiolabeled TR at three different concentrations $(1,10$, and $100 \mu \mathrm{M})$. After 6 -h incubation, cells were quickly spun and resuspended in $1.0 \mathrm{ml}$ of fresh medium. Resuspended cells were pelleted through oil and immediately put on dry ice before homogenization in 10\% TCA $(500 \mu \mathrm{l})$. TCA extracts were neutralized with alamine-freon and loaded on a Partisil 10 SAX HPLC column. HPLC analysis of the drug metabolites is detailed in Methods. (S) denotes sensitivity $(<1.5 \%$ colony survival) and (R) denotes resistance ( $>50 \%$ colony survival), respectively, to TR $\left(10^{-4} \mathrm{M}\right)$ treatment. In no case did the replicate analyses differ from the mean by $>5 \%$. Long-term incubations. Long-term incubations were carried out essentially as described above except that the starting inocula were between $10^{2}$ and $10^{3}$ cells/ $\mathrm{ml}$, the concentrations of tritiated TR was reduced to $0.5 \mu \mathrm{M}$, and the exposure time was extended to $14 \mathrm{~d}$. 
Table II. TAD Synthesis and Its Effects on IMPD Activity in Human Cell Lines Sensitive and Resistant to Tiazofurin

\begin{tabular}{|c|c|c|c|c|c|c|c|}
\hline \multirow[b]{3}{*}{ Cell line } & \multirow[b]{3}{*}{$\begin{array}{l}\text { Sensitivity } \\
\text { to TR }\end{array}$} & \multicolumn{6}{|l|}{ Enzyme activity } \\
\hline & & \multicolumn{2}{|c|}{ NAD-pyrophosphorylase } & \multicolumn{2}{|c|}{ TAD-Phosphodiesterase } & \multicolumn{2}{|l|}{ IMPD } \\
\hline & & Homogenate & Pellet & Homogenate & Supernatant & Supernatant & $\begin{array}{l}\text { Percent inhibition } \\
\text { of IMPD }\end{array}$ \\
\hline & & nmol/h/mg protein & nmol/h/mg protein & nmol/h/mg protein & nmol/h/mg protein & nmol/h/mg protein & \\
\hline H82 & $\mathbf{S}$ & 45 & $56(40)$ & 23 & 47 & 1.4 & 98 \\
\hline N417 & $\mathbf{S}$ & 74 & $92(83)$ & 13 & 34 & 1.5 & 96 \\
\hline $\mathrm{H} 23$ & $\mathbf{S}$ & 90 & $113(130)$ & 18 & 48 & 2.8 & 73 \\
\hline H146 & $\mathbf{R}$ & 15 & $15(13)$ & 87 & 168 & 0.6 & 15 \\
\hline H125 & $\mathbf{R}$ & 41 & $58(61)$ & 85 & 160 & 2.1 & 58 \\
\hline H249 & $\mathbf{R}$ & 5 & $40(45)$ & 78 & 152 & 2.7 & 74 \\
\hline
\end{tabular}

TR, tiazofurin. Experimental details are presented in Methods. Values in parentheses were determined 1 yr after those not bracketed. The specific activity of NAD-pyrophosphorylase in the whole homogenate should be viewed as provisional owing to a strong 5'-nucleotidase and/or phosphatase activity contaminating this preparation; washing substantially reduced this degradative activity from the pellets. Insignificant NAD-pyrophosphorylase activity was demonstrable in the supernatants. Inhibition of IMPD was determined $6 \mathrm{~h}$ after exposure of the cells to $100 \mu \mathrm{M}$ TR.

lines studied, with no correlation to their state of sensitivity or resistance. However, in the drug-treated cells, IMPD activity was inhibited to a greater extent in the sensitive lines (73-98\% inhibition) than in the resistant group (15-74\% inhibition). Measurements of kinetic constants using partially purified IMPD from these six lines showed Michaelis constant $\left(K_{m}\right)$ values (for the substrate, NAD) ranging from 0.4 to $0.8 \mathrm{mM}$, and $K_{\mathrm{i}}$ values (for the inhibitor, TAD) ranging from 0.1 to $0.15 \mu \mathrm{M}$. These constants did not correlate with the sensitive or resistant nature of the lines.

Influence of tiazofurin treatment on nucleotide concentrations. The levels of endogenous purine and pyrimidine nucleotides are shown in Table III. The basal concentrations of these nucleotides were found to be variable among the six lines, with no correlation to their sensitivity or resistance. Tiazofurin treatment $(100 \mu \mathrm{M})$ for $6 \mathrm{~h}$ altered the nucleotide pools in these cells, as documented in Table IV. Thus, guanosine nucleotide concentrations underwent a marked reduction in all three sensitive lines, and, perplexingly, in one of the resistant cell lines; an increase in the IMP pool size accompanied this effect. Pyrimidine nucleotide pools were found to increase in two of the three sensitive, and one of the three resistant strains.

\section{Discussion}

The use of soft agarose clonogenic assays for predicting in vivo responses to chemotherapeutic agents and evaluating new agents has recently achieved clinical application $(14,15,18-$ 21). However, although moderate success is being reported with the use of this approach, the many problems with the cloning of fresh specimens, including adequate colony growth in only $20-50 \%$ of all patient specimens, suggest that the widespread use of this assay will be limited until significant improvements are made in both tumor processing and growth conditions $(9,13,22,23)$.

Table III. Native Nucleotide Concentrations in Cultured Human Lung Tumor Cell Lines Sensitive and Resistant to Tiazofurin

\begin{tabular}{|c|c|c|c|c|c|c|c|c|c|c|}
\hline Cell line & $\begin{array}{l}\text { Sensitivity } \\
\text { to } T R\end{array}$ & AMP & ADP & ATP & GMP & GDP & GTP & IMP & $\begin{array}{l}\text { UMP } \\
\text { TMP }\end{array}$ & $\begin{array}{l}\text { CTP } \\
\text { UTP }\end{array}$ \\
\hline & & $\begin{array}{l}n m o l / m g \\
D N A\end{array}$ & $\begin{array}{l}n m o l / m g \\
D N A\end{array}$ & $\begin{array}{l}n m o l / m g \\
D N A\end{array}$ & $\begin{array}{l}n m o l / m g \\
D N A\end{array}$ & $\begin{array}{l}n m o l / m g \\
D N A\end{array}$ & $\begin{array}{l}n m o l / m g \\
D N A\end{array}$ & $\begin{array}{l}n m o l / m g \\
D N A\end{array}$ & $\begin{array}{l}n m o l / m g \\
D N A\end{array}$ & $\begin{array}{l}\mathrm{nmol} / \mathrm{mg} \\
D N A\end{array}$ \\
\hline H82 & $\mathbf{S}$ & 32 & 43 & 60 & 3 & 7 & 11 & 0.4 & 4 & 11 \\
\hline N417 & $\mathbf{S}$ & 86 & 95 & 94 & 10 & 16 & 23 & 3 & 12 & 16 \\
\hline H23 & $\mathbf{S}$ & 49 & 35 & 112 & 1 & 10 & 36 & 1 & 3 & 48 \\
\hline H146 & $\mathbf{R}$ & 59 & 36 & 28 & 4 & 7 & 6 & 3 & 5 & 5 \\
\hline H125 & $\mathbf{R}$ & 65 & 47 & 86 & 1 & 10 & 12 & 0.1 & 3 & 12 \\
\hline H249 & $\mathbf{R}$ & 75 & 25 & 9 & 9 & 6 & 3 & 2 & 7 & 1 \\
\hline
\end{tabular}

ADP, adenosine diphosphate; CTP, cytidine triphosphate; GDP, guanosine diphosphate; GMP, guanosine monophosphate; GTP, guanosine triphosphate; TMP, thymidine monophosphate; TR, tiazofurin; UMP, uridine monophosphate; UTP, uridine triphosphate. Lung cancer cells growing in $\log$ phase were harvested and centrifuged at $800-1000 \mathrm{~g}$ for $2 \mathrm{~min}$. Cell pellets were quickly washed with ice-cold normal saline and centrifuged at $12,000 \mathrm{~g}$ for $\sim 20 \mathrm{~s}$. Pellets obtained were immediately frozen on dry ice and nucleotides extracted by $10 \%$ TCA treatment. After neutralization, samples were analyzed on HPLC as described in Methods. DNA was measured by the method of Burton (33). The relationship of this parameter to cell number in the six lines, calculated as micrograms of DNA/10 ${ }^{6}$ cells, was as follows: H82:50; N417:50; H23:50; H146: 50; H125:27; H249:60. Data is represented as the mean of at least two determinations which showed <5\% variation. 
Table IV. Influence of Tiazofurin on Nucleotide Concentrations of Human Lung Tumor Cell Lines in Culture

\begin{tabular}{|c|c|c|c|c|c|c|c|c|}
\hline \multirow[b]{3}{*}{ Cell line } & \multirow{3}{*}{$\begin{array}{l}\text { Sensitivity } \\
\text { to TR }\end{array}$} & \multicolumn{5}{|c|}{ Percent of saline control } & \multirow{2}{*}{\multicolumn{2}{|c|}{$\begin{array}{l}\text { Adenosine/guanosine } \\
\text { nucleotides }\end{array}$}} \\
\hline & & \multirow{2}{*}{$\begin{array}{l}\text { Adenosine } \\
\text { nucleotides }\end{array}$} & \multirow{2}{*}{$\begin{array}{l}\text { Guanosine } \\
\text { nucleotides }\end{array}$} & \multirow[b]{2}{*}{ IMP } & \multirow{2}{*}{$\begin{array}{l}\text { UMP } \\
\text { TMP }\end{array}$} & \multirow{2}{*}{$\begin{array}{l}\text { CTP } \\
\text { UTP }\end{array}$} & & \\
\hline & & & & & & & Saline & TR \\
\hline H82 & $\mathbf{S}$ & 71 & 43 & 7500 & 257 & 92 & 6.6 & 10.8 \\
\hline N417 & $\mathbf{S}$ & 63 & 25 & 1017 & 103 & 350 & 5.6 & 14.0 \\
\hline $\mathrm{H} 23$ & $\mathbf{S}$ & 103 & 29 & 1375 & 104 & 203 & 4.1 & 14.7 \\
\hline H146 & $\mathbf{R}$ & 97 & 86 & 424 & 161 & 54 & 6.9 & 7.7 \\
\hline H125 & $\mathbf{R}$ & 80 & 82 & 382 & 87 & 62 & 8.6 & 8.6 \\
\hline H249 & $\mathbf{R}$ & 45 & 29 & 1000 & 67 & 193 & 6.2 & 9.6 \\
\hline
\end{tabular}

CTP, cytidine triphosphate; TMP, thymidine monophosphate; TR, tiazofurin; UMP, uridine monophosphate; UTP, uridine triphosphate. Human cell lines growing in culture were treated with either normal saline or $100 \mu \mathrm{M}$ TR for $6 \mathrm{~h}$. After incubation, cells were quickly centrifuged and the washed pellets were treated with $10 \%$ TCA. Neutralized samples were analyzed by HPLC as described in Methods. Results are represented as the mean of at least two determinations which showed $<5 \%$ variation.

The use of well-established and characterized human cell lines for screening new agents with potential clinical application has several advantages over fresh clinical specimens (24-26). In vitro tests of cytotoxicity can be carried out by many different laboratories using the same panel of cell lines; many different compounds can be evaluated over a wide concentration range because of the availability of an unlimited number of cells; and, most importantly, biochemical correlates of in vitro drug sensitivity can be determined (27). While some studies suggest that, with continuous culture, the chemosensitivity patterns of cell lines may change (24), we have recently shown that both small cell and nonsmall cell lung cancer cells retain in vitro sensitivity to a range of compounds with known clinical activity in the treatment of these tumors $(28,29)$. In addition, in vitro radiation biological studies have correlated well with the clinical radiation responses observed in small cell and nonsmall cell lung cancer patients (28). Thus, the data suggest that serially propagated cultures of human lung cancer cells may have application both for the screening of drugs for phase I/II clinical trials, and, possibly more importantly, for determining mechanisms of resistance to cytotoxic agents.

The present experiments were carried out with six such lines exposed in vitro to the novel oncolytic C-nucleoside, tiazofurin. In three of the lines, clonogenicity was virtually abolished by continuous exposure to $100 \mu \mathrm{M}$ tiazofurin, whereas the three remaining strains proliferated fairly normally at this concentration of drug. The former three cell lines were considered to be sensitive to tiazofurin and the latter three resistant. Although this cut-off is somewhat arbitrary, it is rendered reasonable by pharmacokinetic studies in rodents, rabbits, and dogs, which suggest that blood levels $>100 \mu \mathrm{M}$ are unlikely to be sustained after doses of the drug in the therapeutic range (30); thus, if cell kill is not produed by 100 $\mu \mathrm{M}$ tiazofurin in vitro, it is not likely to be achieved in vivo.

In the metabolic arm of the present study, only one parameter invariably correlated positively with the state of socalled sensitivity or resistance of the lines examined: the concentration of TAD achieved by the cells after exposure to tritiated tiazofurin. At all extracellular concentrations of tiazofurin $(0.5-100 \mu \mathrm{M})$, the resistant lines formed $\sim 5-10$ times less of the dinucleotide than their sensitive counterparts. The constancy of this disparity suggests strongly that is it not a consequence of differential undersaturation, for example, of the TAD-synthesizing system of the resistant lines.

Although NAD pyrophosphorylase is believed to catalyze the formation of TAD (from TRMP and ATP), the specific activity of this enzyme did not correlate in any stringent way with the responsiveness of the six lines examined here. This failure suggests that measurements of NAD pyrophosphorylase in cellular homogenates might not provide an adequate index of the cells' capacity to accumulate TAD (and presumably NAD) in situ.

By contrast, the results of enzymatic measurements of the rate of TAD breakdown, (by 'TAD-phosphodiesterase'), correlated positively with the state of resistance (Table II).

Other parameters whose correlation to sensitivity or resistance was imperfect included: basal IMPD activity; percentage inhibition of IMPD; percentage elevation of IMP following exposure to tiazofurin; and percentage depression of guanosine nucleotides produced by the drug. The failure of this last parameter to correlate with responsiveness or resistance in an absolute way is especially perplexing in view of the proposed mechanism of action of tiazofurin. However, as Table IV documents, in two of the three resistant strains, H146 and $\mathrm{H} 125$, only minor depressions in guanosine nucleotide pools ensued after incubation with tiazofurin. By contrast, in $\mathrm{H} 249$, a $71 \%$ decrease in guanosine nucleotides was produced by the drug and it was this value which skewed the mean.

When taken together, the results of the present studies establish that certain cultured lung tumor cells respond to pharmacologically attainable levels of tiazofurin, whereas certain other lines do not. It is noteworthy that the two SLCL-V cell lines, $\mathrm{H} 82$ and N417, were both sensitive to tiazofurin, while the classic SCLC cell lines, H146 and H249, were resistant to the drug. We have previously shown that these SCLC-V cell lines have a more "malignant" behavior in vitro including higher cloning efficiency and increased tumorigenicity in nude mice than their pure SCLC counterparts (8-11). In addition, SCLC-V cell lines have increased resistance to X-rays in vitro $(28,29)$, and have a high degree of amplification (20-75-fold) of c-myc DNA and greatly increased levels of the c-myc RNA 
(31). Clinical correlates of the SCLC-V have also been observed (32). Patients with the SCLC-V phenotype have a poorer response to chemotherapy, and a shorter survival time than patients with pure SCLC. Whether the increased in vitro sensitivity of the SCLC-V to tiazofurin will translate into clinical efficacy of the drug remains to be seen.

Differential sensitivity with respect to histologic type was not observed for adenocarcinoma cell lines ( $H 23$, ' $S$ ', and $H 125$, ' $R$ '). It is also of interest to note that cell lines $\mathbf{H 8 2}$ and $\mathrm{H} 23$, which were found in previous studies to be resistant to a wide range of oncolytic agents (29), showed sensitivity to tiazofurin treatment in vitro. These data suggest that tiazofurin might be useful in treating lung cancer resistant to standard chemotherapeutic agents. The stability of these cell lines in both their sensitivity to and their metabolic handling of tiazofurin over a 12 mo interval (Table II) reinforces the above contention.

Correlating the cytotoxicity of tiazofurin with its metabolism in vitro, it can be concluded that the measurement of the extent of accumulation of the proximate antimetabolite, TAD, by these six lines was of real predictive value in assessing sensitivity or resistance to the drug. The applicability of this observation to sensitivity or resistance in vivo will be examined in the course of ongoing clinical studies.

\section{Acknowledgments}

The authors thank Ms. Laura Alpert, Ms. Gina Kelsh, and Mrs. Beverly Sisco for their expert help in the preparation of this manuscript.

\section{References}

1. Witkowski, J. T., R. K. Robins, R. W. Sidwell, and L. N. Simon. 1972. Design, synthesis and broad spectrum activity of $1-\beta-D-$ ribofuranosyl-1,2,4-triazole-3-carboxamide and related nucleosides. J. Med. Chem. 15:1150-1154.

2. Robins, R. K., P. C. Srivastava, V. L. Narayanan, J. Plowman, and K. D. Paull. 1982. 2- $\beta$-D-Ribofuranosylthiazole-4-carboxamide, a novel potential anti-tumor agent for lung tumors and metastases. J. Med. Chem. 25:107-108.

3. Earle, M. F., and R. I. Glazer. 1983. Activity and metabolism of 2- $\beta$-D-ribofuranosylthiazole-4-carboxamide in human lymphoid tumor cells in culture. Cancer Res. 43:133-137.

4. Jayaram, H. N., R. L. Dion, R. I. Glazer, D. G. Johns, R. K. Robins, P. C. Srivastava, and D. A. Cooney. 1982. Initial studies on the mechanism of action of a new oncolytic thiazole nucleoside, 2- $\beta$-D-ribofuranosyl-thiazole-4-carboxamide (NSC 286193). Biochem. Pharmacol. 31:2371-2380.

5. Jayaram, H. N., A. I. Smith, R. I. Glazer, D. G. Johns, and D. A. Cooney. 1982. Studies on the mechanism of action of 2- $\beta$-Dribofuranosylthiazole-4-carboxamide (NSC 286193)-II. Relationship between dose level and biochemical effects in P388 leukemia in vivo. Biochem. Pharmacol. 31:3839-3845.

6. Cooney, D. A., H. N. Jayaram, G. Gebeyehu, C. R. Betts, J. A. Kelley, V. E. Marquez, and D. G. Johns. 1982. The conversion of $2-$ $\beta$-D-ribofuranosyl-thiazole-4-carboxamide to an analogue of NAD with potent IMP dehydrogenase-inhibitory properties. Biochem. Pharmacol. 31:2133-2136.

7. Cooney, D. A., H. N. Jayaram, R. I. Glazer, J. A. Kelley, V. E. Marquez, G. Gebeyehu, A. C. Van Cott, L. A. Zwelling, and D. G. Johns. 1983. Studies on the mechanism of action of tiazofurin. Metabolism to an analog of NAD with potent IMP dehydrogenaseinhibitory activity. Adv. Enzyme Regul. 21:271-303.
8. Gazdar, A. F., D. N. Carney, E. K. Russel, H. L. Simms, S. B. Baylin, P. A. Bunn, Jr., J. G. Guccion, and J. D. Minna. 1980. Small cell carcinoma of the lung: establishment of continuous clonable cell lines having APUD properties. Cancer Res. 40:3502-3507.

9. Carney, D. N., P. A. Bunn, A. F. Gazdar, J. A. Pagan, and J. D. Minna. 1981. Selective growth in serum-free hormone supplemented medium of tumor cells obtained by biopsy from patients with small cell carcinoma of the lung. Proc. Natl. Acad. Sci. USA. 78:31853189.

10. Gazdar, A. F., D. N. Carney, and J. D. Minna. 1983. The biology of non-small cell lung cancer. Semin. Oncol. 1:3-19.

11. Carney, D. N., L. Broder, M. Edelstein, A. F. Gazdar, M. Hansen, K. Havwemann, M. J. Matthews, G. D. Sorensen, and L. Vindelov. 1983. Experimental studies of the biology of human small cell lung cancer. Cancer Treat. Rep. 57:27-35.

12. Carney, D. N., A. F. Gazdar, and J. D. Minna. 1980. Positive correlation between histologic tumor involvement and generation of tumor cell colonies in agarose in specimens taken directly from patients with small cell carcinoma of the lung. Cancer Res. 40:1820-1823.

13. Carney, D. N., A. F. Gazdar, P. A. Bunn, and J. G. Guccion. 1981. Demonstration of the stem cell nature of the clonogenic cells in lung cancer specimens. Stem Cells. 1:149-164.

14. Salmon, S. E., A. W. Hamburger, B. J. Soehnlen, B. G. M. Durie, D. S. Alberts, and T. C. Moon. 1978. Quantitation of differential sensitivities of human tumor stem cells to anticancer drugs. N. Engl. J. Med. 298:1321-1327.

15. Von Hoff, D. D., J. Casper, E. Bradley, J. Sandbach, D. Jones, and R. Makuch. 1981. Association between human tumor colonyforming assay results and response of an individual patient's tumor to chemotherapy. Am. J. Med. 70:1027-1032.

16. Khym, J. X. 1975. An analytical system for rapid separation of tissue nucleotides at low pressures on conventional anion exchangers. Clin. Chem. 21:1245-1252.

17. Pinder, S., J. B. Clark, and A. L. Greenbaum. 1971. The assay of intermediates and enzymes involved in the synthesis of the nicotinamide nucleotides in mammalian tissues. Methods Enzymol. 18:2046.

18. Ozols, R. F., J. K. V. Willson, M. D. Weltz, K. R. Grotzinger, C. E. Myers, and R. C. Young. 1980. Inhibition of human ovarian cancer colony formation by adriamycin and its major metabolites. Cancer Res. 40:4109-4114.

19. Von Hoff, D. D., C. A. Coltman, and B. Forseth. 1981. Activity of mitoxantrone in a human tumor cloning system. Cancer Res. 41:1853-1855.

20. Salmon, S. E., F. L. Meyskens, D. S. Alberts, B. Soehnlen, and L. Young. 1981. New drugs in ovarian cancer and malignant melanoma in vitro phase II screening with the human tumor stem cell assay. Cancer Treat. Rep. 65:1-12.

21. Von Hoff, D. D., J. Gutterman, B. Portnoy, and C. A. Coltman. 1982. Activity of human leukocyte interferon in a human tumour cloning system. Cancer Chemother. Pharmacol. 8:99-103.

22. Rupniak, H. T., and B. T. Hill. 1980. The poor cloning ability in agar of human tumor cells from biopsies of primary tumors. Cell Biol. Int. Rep. 4:479-486.

23. Bertoncello, L., T. R. Bradley, J. J. Campbell, A. J. Day, I. A. McDonald, G. R. McLeish, M. A. Quinn, R. Rome, and G. S. Hodgson. 1982. Limitations of the clonal agar assay for the assessment of primary human ovarian tumour biopsies. Br. J. Cancer. 45:803811.

24. Tveit, K. M., O. Fodstad, and A. Pihe. 1981. The usefulness of human tumour cell lines in the study of chemosensitivity. A study of malignant melanoma. Int. J. Cancer. 28:403-408.

25. Siegel, M. M., H. S. Chung, N. Rucker, S. E. Siegel, R. C. Seeger, H. Isaacs, Jr., and W. F. Benedict. 1980. In vitro and in vivo preclinical chemotherapy studies of human neuroblastoma. Cancer Treat. Rep. 64:975-979.

26. Kornblith, P. L., B. H. Smith, and L. A. Leonard. 1981. 
Response of cultured human brain tumours to nitrosoureas. Cancer. 47:255-265.

27. Curt, G. A., D. N. Carney, K. H. Cowan, J. Jolivet, B. D. Bailey, J. C. Drake, C. S. Kao-Shan, J. D. Minna, and B. A. Chabner. 1983. Unstable methotrexate resistance in human small cell carcinoma associated with double minute chromosomes. N. Engl. J. Med. 308:199203.

28. Carney, D. N., J. B. Mitchell, and T. J. Kinsella. 1983. In vitro radiation and chemosensitivity of established cell lines of human small cell lung cancer and its large cell variants. Cancer Res. 43:2806-2811.

29. Carney, D. N., M. Brower, G. Morstyn, J. B. Mitchell, and T. J. Kinsella. 1984. Clinical and laboratory sensitivity of human lung cancer to chemotherapy and irradiation: correlation with endocrine properties. In Endocrine Lung in Health and Disease. K. L. Becker, and A. F. Gazdar, editors. W. B. Saunders Co. 603-611.

30. Arnold, S. T., H. N. Jayaram, G. R. Harper, C. L. Litterst, L.
Malspeis, J. V. DeSouza, A. E. Staubus, G. S. Ahluwalia, Y. A. Wilson, D. A. Cooney, and D. G. Johns. 1984. The disposition and metabolism of tiazofurin in rodents, rabbits and dogs. Drug Metab. Dispos. 12:165173.

31. Little, C. D., M. M. Nau, D. N. Carney, A. F. Gazdar, and J. D. Minna. 1983. Amplification and expression of the c-myc oncogene in human lung cancer cells. Nature (Lond.). 306:194-196.

32. Radice, P. A., M. J. Matthews, D. C. Ihde, A. F. Gazdar, D. N. Carney, P. A. Bunn, M. H. Cohen, B. E. Fossieck, R. W. Makuch, and J. D. Minna. 1982. The clinical behavior of mixed small cell/large cell bronchogenic carcinoma compared to pure small cell subtypes. Cancer. 50:2894-2902.

33. Burton, K. 1956. A study of the conditions and mechanisms of the diphenylamine reaction for the colorimetric estimation of deoxyribonucleic acid. Biochem. J. 62:315-323. 